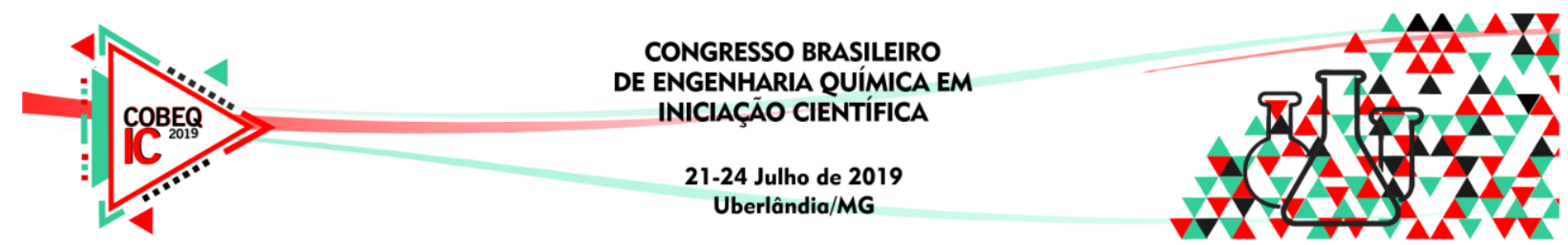

\title{
ANÁLISE DE FITOTOXICIDADE DO HERBICIDA GLIFOSATO (ROUNDUP)
}

\author{
K. B. dos SANTOS, T. C. S. SAMPAIO, A. B. N. ARAUJO e D.C. da SILVA \\ Universidade Federal de Mato Grosso, Faculdade de Engenharia \\ E-mail para contato: pglifosato@gmail.com
}

\begin{abstract}
RESUMO - Tendo em vista a grande utilização do herbicida glifosato no Estado de Mato Groso, o presente trabalho analisou a fitotoxicidade em sementes de alface (Lactuca sativa) e rúcula (Eruca sativa), hortaliças amplamente consumida pelos ribeirinhas. Os biotestes resumem-se em utilizar, sementes distribuídas uniformemente sobre algodão umedecido em placas de Petri na presença de diferentes concentrações de glifosato. Como resultado, foi possível verificar o efeito tóxico mais evidente do glifosato nas sementes de alface por meio da germinação absoluta, do crescimento relativo da raiz e do índice de germinação. Desta forma, as sementes de rúcula e alface podem ser utilizadas em biotestes de fitotoxicidade à exposição do herbicida glifosato.
\end{abstract}

\section{INTRODUÇÃO}

O comércio mundial de pesticidas vem crescendo a cada ano, com ressalta no Estado de Mato Grosso, que se destaca pela produção de soja (Embrapa Soja safra 2015/2016). Anualmente, ocorrem variáveis mudanças na produção de sementes conforme as necessidades do mercado, entre essas estão o advento das culturas transgênicas, resistentes a algumas pragas e não ao florescimento de ervas daninhas. Neste sentido, necessita-se do uso de herbicida.

Um dos herbicidas mais utilizados de acordo com Junior et. al (2001) é o glifosato (N(fosfonometil)glicina) que tem como propriedade ser não-seletivo, sistêmico e pós-emergente. Ele representa $60 \%$ do mercado mundial de herbicidas não seletivos e é o mais utilizado em plantações de soja transgênica.

Uma das mais importantes características do glifosato em plantas tratada com o mesmo é sua rápida translocação das folhas para as raízes, rizomas e meristemas apicais. Esta propriedade sistêmica resulta na destruição total de plantas, não tendo ação somente nas plantas, mas também em sementes no solo, mostrando assim o grau de toxidade que o herbicida possui (YAMADA \& CAMARGO, 2007).

No presente estudo as sementes selecionadas para a realização dos experimentos foram de alface e rúcula. As mesmas foram escolhidas, em relação à pesquisa realizada por Amaral et. al (2008) que constatou um grande consumo destas hortaliças pelos ribeirinhas no Estado de Mato Grosso. 


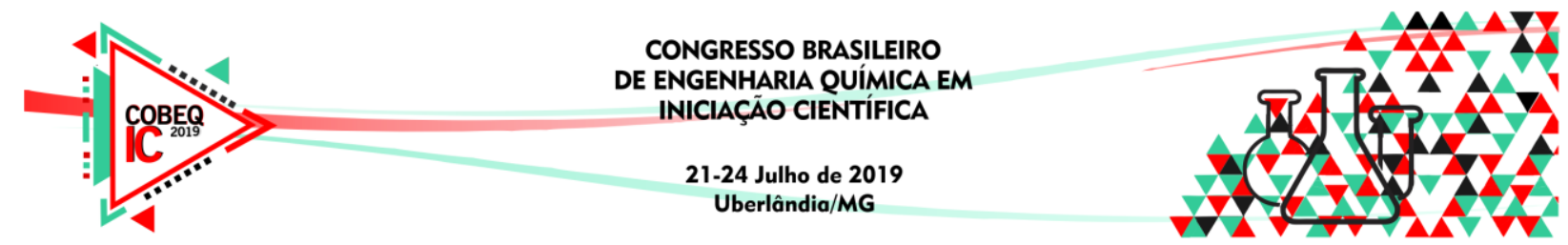

Desta forma, o trabalho teve como objetivo calcular os parâmetros: germinação absoluta (\%GA); crescimento relativo da raiz (\%CRR) e índice de germinação (\% IG) em alface (Lactuca sativa) e rúcula (Eruca sativa) e assim avaliar a influência do herbicida glifosato na germinação dessas sementes e a viabilidade da utilização da alface e da rúcula como modelo em bioteste de fitotoxicidade.

\section{METODOLOGIA}

A pesquisa foi realizada em parceria com o Laboratório de Pesquisa, Universidade Federal de Mato Grosso, Departamento de Engenharia Sanitária e Ambiental, Cuiabá MT. Os testes com as sementes não são padronizadas, e neste trabalho utilizou-se como referências o trabalho de Simões e colaboradores (2013) e as Regras para Análise de Sementes (RAS) do Ministério da Agricultura, Pecuária e Abastecimento (2009).

Os ensaios toxicológicos foram realizados em placas Petri, de $90 \mathrm{~mm}$ de diâmetro, com as espécies vegetais Lactuca sativa e Eruca sativa, popularmente conhecidas como Alface Elba e Rúcula, respectivamente. Sendo assim, em cada tipo de vegetal, foram utilizadas 30 placas, distribuídas para seis tipos de concentrações (controle - água da torneira; $12,5 \%$; 25\%; $50 \% ; 75 \%$; $100 \%$ ) de acordo com a resolução do CONAMA 357/2005 para o herbicida Glifosato $65 \mu \mathrm{g} \mathrm{L}{ }^{-1}$.

Para as respectivas concentrações foram realizadas cinco repetições. Cada placa continha, 1,28 g de algodão e 20 sementes sobre o mesmo. Entretanto, para cada vegetal, o tempo de germinação e o crescimento foram diferentes de acordo com o RAS (Brasil, 2009), Tabela 1.

Tabela 1 - Espécies vegetais utilizadas no experimento com a temperatura recomendada para realização dos testes de germinação $\left(1^{\circ}\right)$ e teste de crescimento (final).

\begin{tabular}{|c|c|c|c|}
\hline Espécie Botânica & $\begin{array}{c}\text { Temperatura em } \\
{ }^{\circ} \mathrm{C}\end{array}$ & \multicolumn{2}{|c|}{ Contagem em dias } \\
\cline { 3 - 4 } & & $1^{\mathrm{a}}$ & Final \\
\hline Lactuca sativa & 20 & 4 & 7 \\
\hline Eruca sativa & 20 & 4 & 7 \\
\hline
\end{tabular}

Fonte: RAS (Brasil, 2009).

Os bioensaios foram fundamentados nos parâmetros (germinação absoluta - \%GA, crescimento relativo da raiz - \%CRR, índice de germinação - \%IG) apresentados em GOMES, et al. (2009) apud TIQUIA, et al. (1996).

$$
\begin{aligned}
& \% G A=\frac{\mathrm{n}^{\circ} \text { de sementes que germinaram } \times 100}{\mathrm{n}^{\circ} \text { de sementes totais }} \\
& \% C R R=\frac{\text { média do comprimento da raiz } \times 100}{\text { média do comprimento no controle }}
\end{aligned}
$$




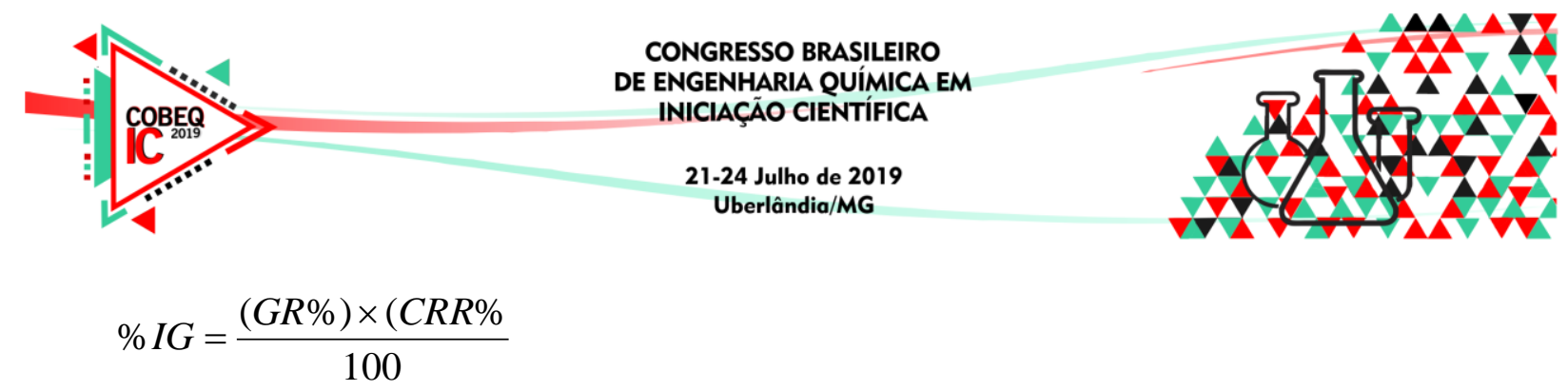

Sendo assim, após o tempo de desenvolvimento dos vegetais, o número de sementes germinadas foram contabilizadas e o comprimento das plântulas e radículas foi mensurado.

\section{RESULTADOS E DISCUSSÕES}

Os resultados obtidos no estudo da germinação de sementes de rúcula e alface estão apresentados na Tabela 2 e 3, sendo considerado como raiz, a radícula mais o hipocótilo.

Tabela 2 - Análise de germinação da semente de rúcula

\begin{tabular}{|c|c|c|c|c|c|}
\hline Parâmetros & $\begin{array}{c}\text { Média } \pm \text { desvio } \\
\text { padrão - semente } \\
\text { Germinada }\end{array}$ & $\begin{array}{c}\text { Tamanho médio das } \\
\text { raízes } \pm \text { desvio } \\
\text { padrão }(\mathrm{cm})\end{array}$ & \%GA & \%CRR & \% IG \\
\hline Controle & $16,0 \pm 2,82$ & $4,44 \pm 0,59$ & 80,0 & - & - \\
\hline $12,5 \%\left(16,25 \mu \mathrm{g} \mathrm{L}^{-1}\right)$ & $16,5 \pm 1,95$ & $4,28 \pm 0,19$ & 82,5 & 96,25 & 79,40 \\
\hline $25 \%\left(32,5 \mu \mathrm{g} \mathrm{L}^{-1}\right)$ & $16,1 \pm 2,49$ & $4,69 \pm 0,41$ & 80,5 & 105,53 & 84,95 \\
\hline $50 \%\left(65 \mu \mathrm{g} \mathrm{L}^{-1}\right)$ & $17,6 \pm 1,51$ & $4,15 \pm 0,53$ & 88,0 & 93,52 & 82,29 \\
\hline $75 \%\left(97,5 \mu \mathrm{g} \mathrm{L}^{-1}\right)$ & $18,8 \pm 1,09$ & $4,67 \pm 0,34$ & 94,0 & 105,25 & 98,94 \\
\hline $100 \%\left(130 \mu \mathrm{g} \mathrm{L}^{-1}\right)$ & $18,0 \pm 1,41$ & $4,33 \pm 0,43$ & 90,0 & 97,5 & 87,75 \\
\hline
\end{tabular}

Tabela 3 - Análise de germinação da semente de Alface

\begin{tabular}{|c|c|c|c|c|c|}
\hline Parâmetros & $\begin{array}{c}\text { Média } \pm \text { desvio } \\
\text { padrão - semente } \\
\text { Germinada }\end{array}$ & $\begin{array}{c}\text { Tamanho médio das } \\
\text { raízes } \pm \text { desvio } \\
\text { padrão }(\mathrm{cm})\end{array}$ & $\% \mathrm{GA}$ & \%CRR & \%IG \\
\hline Controle & $19,8 \pm 0,45$ & $4,87 \pm 0,24$ & 99,0 & - & - \\
\hline $12,5 \%\left(16,25 \mu \mathrm{g} \mathrm{L}^{-1}\right)$ & $19,8 \pm 0,45$ & $5,24 \pm 0,50$ & 99,0 & 107,62 & 106,55 \\
\hline $25 \%\left(32,5 \mu \mathrm{g} \mathrm{L}^{-1}\right)$ & $19,6 \pm 0,55$ & $6,04 \pm 0,13$ & 98,0 & 124,15 & 121,66 \\
\hline $50 \%\left(65 \mu \mathrm{g} \mathrm{L}^{-1}\right)$ & $18,4 \pm 1,82$ & $6,17 \pm 0,26$ & 92,0 & 126,80 & 116,66 \\
\hline $75 \%\left(97,5 \mu \mathrm{g} \mathrm{L}^{-1}\right)$ & $18,4 \pm 1,14$ & $5,75 \pm 1,50$ & 92,0 & 118,16 & 108,71 \\
\hline $100 \%\left(130 \mu \mathrm{g} \mathrm{L}^{-1}\right)$ & $18,0 \pm 1,58$ & $4,69 \pm 0,46$ & 90,0 & 96,28 & 86,65 \\
\hline
\end{tabular}

Os parâmetros apresentam as concentrações utilizadas nos biotestes, tendo como base a concentração de $65 \mu \mathrm{g} \mathrm{L}^{-1}$ estabelecida pelo CONAMA n ${ }^{\circ}$ 357/2005 como aceitável para lançamentos em efluentes de rio de classe II. A média de semente germinada e o tamanho médio das raízes relacionam a quantidade de sementes que germinaram e o seu desenvolvimento nas cinco placas, utilizadas para cada parâmetro.

Para as sementes de rúcula, observou-se, um aumento na quantidade de sementes germinadas a medida em que as concentrações aumentavam, do mesmo modo que o tamanho das raízes para o controle foi levemente superior à concentração de $100 \%$. Em contrapartida, para a alface, notou-se uma redução na quantidade de sementes germinadas conforme o aumento das concentrações utilizadas. Percebeu-se também, que ocorreu um aumento progressivo no tamanho das raízes até a concentração de $50 \mu \mathrm{g} \mathrm{L}^{-1}$ e a seguinte uma diminuição. 


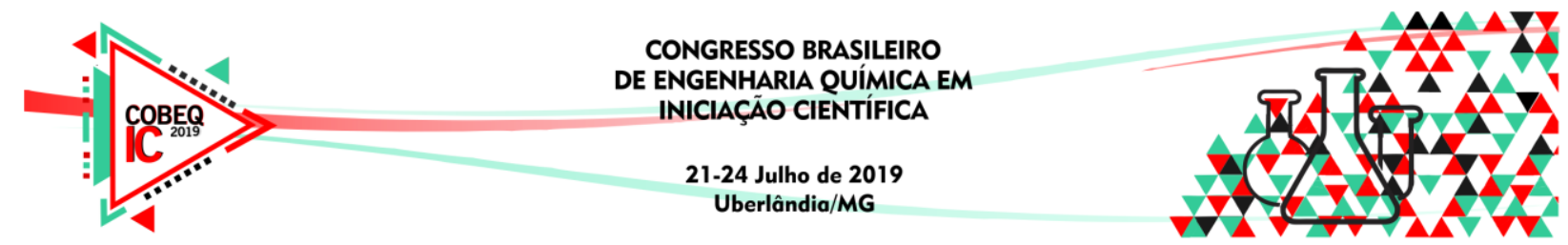

Verificou-se por meio dos cálculos, que o índice de germinação absoluta para as sementes de rúcula, apresentou um aumento em relação ao controle. Por outro lado, notou-se que para as sementes de alface ocorreu uma diminuição no índice de germinação absoluta e no índice de germinação ao passo em que as concentrações aumentavam em relação ao controle.

Diante dos dados obtidos, observa-se que para as sementes de rúcula o glifosato causou um aumento no índice de germinação absoluta, divergentemente do que foi observado, em Rebessi et al. (2011), provavelmente pode ser devido a unidade de concentração $\left(\mathrm{mg} \mathrm{L}^{-1}\right)$ utilizada pelo pesquisador, em visto que no presente trabalho foi utilizada concentração na medida $\mu \mathrm{g} \mathrm{L}^{-1}$. Notou-se também uma coloração mais forte e espessura mais grossa do hipocótilo nas sementes que foram submetidas às menores concentrações quando comparadas as de concentração maior. Nas sementes sujeitas à concentração de $130 \mu \mathrm{g} \mathrm{L}^{-1}$ percebeu-se que algumas apresentaram queimaduras quando comparadas com controle.

Em relação às sementes de alface, observou-se um comportamento contrário aos resultados apresentados pela semente rúcula. A Alface mostrou-se mais sensível para a toxidade do glifosato, diminuindo visivelmente seu índice de germinação. Vale ressaltar, que em outros estudos também comprovaram esta sensibilidade ao glifosato, como na pesquisa realizada por Nascimento et al. (2009) que estudou o efeito toxicológico do glifosato em sementes de alface nas concentrações de $10-50 \mathrm{mg} \mathrm{L}^{-1}$ e Sousa et al. (2014) que estudou o efeito toxicológico do glifosato diretamente no solo utilizando sementes de alface.

Portanto, as sementes de alface mostraram-se mais sensível à toxidade do herbicida glifosato em relação às sementes de rúcula. Deve-se ao fato, da sensibilidade que as sementes de alface são mais utilizadas para testes de fitotoxicidade.

\section{CONCLUSÃO}

Em vista dos métodos mencionados, concluiu-se que o herbicida glifosato interferiu na germinação e no desenvolvimento das sementes de alface e rúcula, sendo mais evidente a sua toxidade na alface. Por fim, a alface mostrou-se mais eficiente para bioteste de fitotoxicidade.

\section{REFERÊNCIAS}

AMARAL, C. N.; NETO, G. G. Os quintais como espaços de conservação e cultivo de alimentos: um estudo na cidade de Rosário Oeste (Mato Grosso Brasil). Ciências Humanas, Belém, v. 3, n. 3, p. 329-341, set.- dez. 2008.

BRASIL, MINISTÉRIO DA AGRICULTURA. Regras para análise de sementes. Brasília: Departamento Nacional de Produção Vegetal, 2009. 365 p.

BRASIL. resolução $n^{o}$ 357, de 17 de março de 2005.

EMBRAPA. Relatório da safra 2015/2016 no Estado do Mato Grosso. Sinop, MT: Embrapa, 2017.

GOMES, G.; VILlELA, A.; MACIEL, J.; CARVALHO, I.; SILVA, P.; SOUSA, M. F. Fitotoxicidade dos materiais residuais provenientes da degradação de petroderivados por Rhodotorula aurantiaca. In: IX JORNADA DE ENSINO, PESQUISA E 


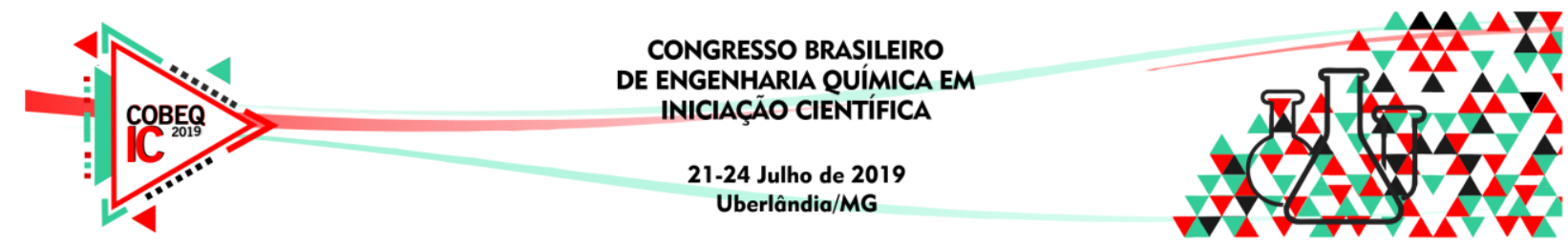

EXTENSÃO, JEPEX, 2009. Recife. Disponível em: <http://www.eventosufrpe.com.br/jepex2009/cd/resumos/R1359-2.pdf >. Acesso em: 17 jan. 2017.

JUNIOR, O. P. A.; SANTOS, T. C. R.; BRITO, N. M.; RIBEIRO, M. L. Glifosato: propriedades, toxicidade, usos e legislação. Química Nova, Quim. Nova, Vol. 25, No. 4, 589-593, 2002.

NASCIMENTO A. P. et al. Estudo da toxicidade crônica do herbicida glifosato para as sementes de salsa, alface e coentro. BioEng, Campinas, 3 (2): 149-160, mai/ago., 2009.

REBESSI, A. C. et al. Estudo da toxicidade crônica do herbicida glifosato em sementes de milho, de quiabo e rúcula. Engenharia Ambiental. Espírito Santo do Pinhal, v. 8, n. 2, p. 017-027, abr./jun. 2011.

SIMÕES, M. S.; MADAIL, R. H.; BARBOSA, S.; NOGUEIRA, M. L. Padronização de bioensaios para detecção de compostos alelopáticos e toxicantes ambientais utilizando alface. Revista Biotemas, 26 (3), setembro de 2013.

SOUSA, D. T.; NOCITI, L. A. S.; SILVA E CASTRO, L. H. Resíduos de agrotóxicos no solo sobre a germinação e crescimento de alface (Lactuca sativa) e rabanete (Raphanus sativus). Nucleus, v.11, n.2, out.2014.

YAMADA T.; CAMARGO P.R. Efeitos do glifosato nas plantas: implicações fisiológicas e agronômicas. Informações Agronômicas , Piracicaba,SP, n.. 119 - setembro/ 2007. 